\title{
Participación ciudadana e interpretación de la constitución. Análisis de la jurisprudencia de la Corte Constitucional colombiana en materia de democracia participativa* $^{*}$
}

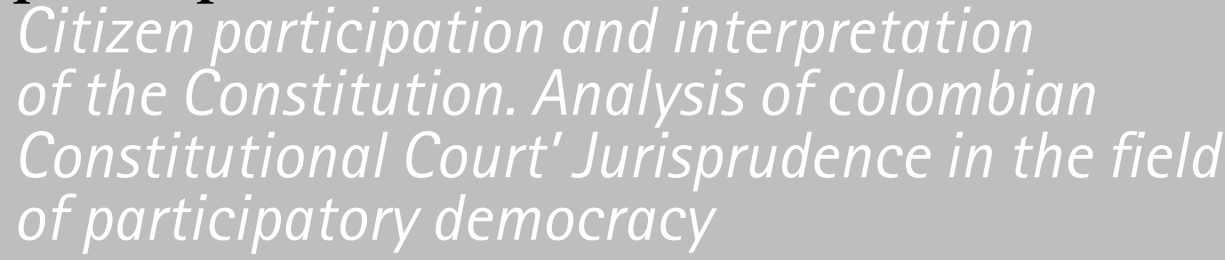

\section{Alfredo Ramírez Nárdiz**}

\section{RESUMEN}

La democracia participativa es uno de los pilares del nuevo modelo constitucional que consagra la Constitución Política de Colombia de 1991, texto que, en muchos aspectos, supone el pistoletazo de salida del conocido como nuevo constitucionalismo latinoamericano. Dicha corriente considera como uno de sus elementos nucleares el fomento de la participación directa de los ciudadanos en la vida pública en general y en la toma de decisiones politicas en particular. Desde sus primeros años de existencia, la Corte Constitucional colombiana ha citado y valorado la democracia participativa. Es objeto de este texto analizar esta jurisprudencia y exponer cuáles han sido sus principales líneas doctrinales desde los años noventa hasta el presente. Se concluye que, desde el primer

\begin{abstract}
Participatory Democracy is one of the pillars of the new constitutional model that was established as the Political Constitution of Colombia of 1991, a text which, in many respects, represents the starting point of what has come to be known as New Latin American Constitutionalism. This concept considers as one of its nuclear elements the promotion and increase of the direct participation of citizens in the public life in general, and in the political decision making in particular. From its first years of existence the Colombian Constitutional Court has cited and valued participatory democracy. The object of this paper is to analyze this jurisprudence and to expose what have been its main doctrinal lines from 1990s to the present. It is concluded
\end{abstract}

\footnotetext{
* Recibido: 12 de agosto de 2015. Aceptado: 19 de septiembre de 2015.

** Profesor en la Universidad Libre, Barranquilla, Colombia. (alfredoramireznardiz@hotmail.com)
} 
momento, la Corte Constitucional apostó por la democracia participativa y consideró su fomento como esencial para el desarrollo y consolidación de la democracia colombiana contemporánea.

PALABRAS ClaVE: Colombia, Corte Constitucional, democracia participativa, participación ciudadana. that, from the first moment, the Constitutional Court supported participatory democracy and considered its promotion as essential for the development and consolidation of modern Colombian democracy.

KEY WORDS: Colombia, Constitutional Court, participatory democracy, citizenship participation.

\section{SUMARIO}

1. Introducción

2. Conceptualización de la democracia participativa

3. La participación como elemento nuclear de la Constitución Política de Colombia de 1991

4. Análisis de la jurisprudencia de la Corte Constitucional de Colombia en materia de democracia participativa

5. Conclusiones

\section{Introducción ${ }^{1}$}

El proceso constituyente colombiano de 1991 surge, en no poca medida, de un movimiento participativo ciudadano popularmente conocido como la "Séptima Papeleta”, el cual promovió que, a principios de los años noventa, no se hiciera una mera reforma a la Constitución de 1886, sino que, como ratificó la Corte Suprema, se hiciera un proceso constituyente que diera lugar a una nueva Constitución: la Constitución Política de 1991 . $^{2}$ Esta nueva Constitución es, para diversos autores, ${ }^{3}$ el comienzo del movimiento constitucional popularmente conocido como nuevo constitucionalismo latinoamericano. Uno de sus elementos esenciales es el aumento de la participación de los ciudadanos en la vida pública y, especialmente, en la toma de decisiones políticas.

\footnotetext{
${ }^{1}$ El presente artículo es fruto del proyecto de investigación Transformaciones Democráticas y Democracia Participativa del grupo Poder Público y Ciudadanía de la Universidad Libre, Barranquilla, Colombia. Ha sido realizado con la participación del semillero de investigación formado por los alumnos Natali Escorcia Ospino, Sara Cañas González, Maria Claudia Pacheco Aarón y Lenin Miguel Vizcaino Rodríguez.

${ }^{2}$ Leiva-Ramirez, Eric y Muñoz-González, Ana Lucia. "El poder constituyente y la carta de derechos en la Constitución Política de Colombia de 1991", en Administración y desarrollo, vol. 39, No. 54, 2011, pp. 119-132.

${ }^{3}$ Noguera Fernández, Albert y Criado de Diego, Marcos. "La Constitución colombiana de 1991 como punto de inicio del nuevo constitucionalismo en América Latina", Revista Estudios Socio-Jurídicos, vol. 13, No. 1, 2011, pp. 15-49.
} 
Efectivamente, la Constitución de 1991 asume ya desde su primer artículo la participación como uno de los elementos que constituyen el núcleo del texto constitucional. ${ }^{4}$ Este principio se desarrolla no sólo en el propio articulado de la Carta Magna colombiana, sino en diversas leyes que lo desarrollan ${ }^{5} \mathrm{y}$, desde 1994, en la jurisprudencia de la por entonces muy joven Corte Constitucional de Colombia. ${ }^{6}$

Partiendo de la asunción general de que la Corte Constitucional toma una evidente aproximación positiva para con la democracia participativa (pues la propia Constitución así lo determina), ${ }^{7}$ y con la finalidad última de prever cuáles podrán ser los futuros desarrollos de la jurisprudencia constitucional colombiana, resulta de interés analizar su desarrollo de las tres últimas décadas en esta materia, para extraer las líneas doctrinales maestras que han determinado el devenir de la democracia participativa colombiana desde la aprobación de la Constitución.

Para ello, resulta necesario, en primer lugar, plantear qué se entiende por democracia participativa. Trataremos de resolver cualquier confusión tanto conceptual, como terminológica, muy habituales en este ámbito jurídico. A continuación, expondremos con cierto detalle la regulación constitucional y legal de la democracia participativa en Colombia. Haremos referencia, aunque sea brevemente, a su práctica y experiencia más destacada. Finalmente, analizaremos la jurisprudencia constitucional que desde 1994 ha producido la Corte Constitucional.

Resulta especialmente interesante plantear hasta qué punto la jurisprudencia constitucional ha tenido efectos reales en el desarrollo de la democracia participativa colombiana, si la práctica de la misma ha seguido las líneas determinadas por la alta corte y si el futuro inmediato se presenta favorable o no a que estas guías de la Corte se materialicen. ${ }^{8}$

\footnotetext{
${ }^{4}$ Indica el artículo 1 que "Colombia es un Estado social de derecho, organizado en forma de República unitaria, descentralizada, con autonomía de sus entidades territoriales, democrática, participativa y pluralista".

${ }^{5}$ Particularmente las leyes 131 y 134 de 1994.

${ }^{6}$ Tomando en cuenta que los fallos de la Corte Constitucional "sobre revisión de constitucionalidad [sic] son obligatorios y vinculantes para todos los operadores judiciales; no asi los fallos expedidos en procesos de revisión de tutelas, que, por carecer de una disposición constitucional expresa, no son obligatorios, pero sí vinculantes". Molinares HASSAN, VIRIDIANA. "Justicia constitucional casos de protección a la libertad y seguridad personal en Colombia", Revista Estudios Socio-Juridicos, vol. 16, No. 2, 2014, p. 92.

${ }^{7}$ Bien indican Patarroyo Rengifo y Forero Castillo que "la Corte Constitucional Colombiana durante toda su historia ha realizado un activismo judicial progresista, cuya finalidad ha sido la realización de los principios establecidos en la Carta Política de 1991; para que no se queden en letra muerta". Patarroyo Rengifo, Santiago y Forero Castillo, Nancy AndREA. "La Corte Constitucional frente al derecho a la educación para la población LGBtI", Revista Via luris, No. 12, 2012, p. 69.

${ }^{8} \mathrm{Sin}$ olvidar que la labor interpretativa de la Corte Constitucional es "expresión de la razón pública frente a los debates jurídicos, políticos y sociales que se llevan a cabo en este pais". AguirRe Román, Javier, Silva Rojas, Alonso y Pabón
} 
Desde las presentes líneas se pretende, por tanto, responder a estas cuestiones; trataremos de elaborar una sistematización mínima de la jurisprudencia constitucional colombiana sobre democracia participativa, su pasado, su presente y, aunque sea a modo de hipótesis, su futuro próximo.

\section{Conceptualización de la democracia participativa}

A modo de propuesta, es posible plantear que la democracia participativa es el conjunto de instrumentos participativos (desde referendos, hasta presupuestos participativos) que busca complementar la democracia representativa mediante una mayor participación política directa y un mayor control de los ciudadanos sobre sus gobernantes, con el objetivo último de profundizar y mejorar la democracia. ${ }^{9}$

El término democracia participativa es reciente. Se puede fijar su aparición entre los sesenta y setenta del siglo $\mathrm{xx}$, como parte del movimiento participacionista que surgió en aquellos años y que tiene por fin acercar la democracia a los ciudadanos; considera que se había entrado en una dinámica elitista que la alejaba de ellos. ${ }^{10}$ Usualmente, dicho término se presta a la confusión por ser habitual, tanto en textos normativos como en los autores, o en la propia jurisprudencia, por referirse al concepto al que hace referencia con otros términos alternativos que suelen solaparse con él. ${ }^{11}$ El propio concepto no es de aceptación unánime, y lo que se considere propio de él dependerá igualmente de la fuente legal, doctrinal o jurisprudencial a la que se acuda. ${ }^{12}$

Desde estas líneas, sabiendo que es una propuesta entre otras posibles, se propone una diferenciación conceptual entre democracia participativa y participación ciudadana que haga girar la diferencia entre una y otra. En la primera, la participación de los ciudadanos implica la toma de decisiones (vinculantes o no; inicien el proceso legislativo o lo terminen); en la segunda, la participación de los ciudadanos no supone necesariamente la toma de decisiones (puede

Mantllla, Ana Patricia. "Eutanasia, estado constitucional y democracia: la validez de los argumentos religiosos en las decisiones de la Corte Constitucional Colombiana a la luz de la propuesta de Habermas sobre el rol de la religión en la esfera pública", Opinión Jurídica, Universidad de Medellín, vol. 14, No. 27, 2015, p. 55.

${ }^{9}$ Ramirez Nárdiz, Alfredo. Guía práctica de la democracia participativa. Conocer la democracia participativa y aprender a usarla, Dykinson, Madrid, 2012, p. 109.

${ }^{10}$ Destacados en este punto son los argumentos de Habermas, quien cuestiona la capacidad que una democracia de élites tiene para servir los intereses de la mayoría de los ciudadanos. HABERMAS, Jurgen. Facticidad y validez. Sobre el derecho y el Estado democrático de derecho en términos de teoría del discurso, Trotta, Madrid, 1998, pp. 410-411.

"Véase el glosario en Ramirez Nárdiz, Alfredo. Op. cit., 2012.

${ }^{12}$ Así, por ejemplo, en España, la STC 103/2008 de 11 de septiembre distingue entre democracia directa (los instrumentos participativos que regula la Constitución) y fenómeno participativo (todas las formas de participación del ciudadano en la vida pública, incluidas aquellas derivadas de derechos distintos al de participación política recogido en el artículo $23 \mathrm{cE}$, sin hacer referencia alguna a la expresión democracia participativa. 
limitarse su ejecución al intercambio de información con el poder político, por ejemplo). ${ }^{13}$ Se opta por esta diferenciación conceptual frente a posibles utilizaciones políticas de los términos que tratarán de obtener rédito del valor positivo de todo lo relacionado con la participación, pero hurtando en la práctica a los ciudadanos la misma limitándose a ofrecerles un sucedáneo que no les permitiera decidir. Igualmente, se opta por desechar expresiones como democracia directa (o semidirecta) o fenómeno participativo. La primera se considera más propia de pasados remotos o de realidades utópicas; la segunda, demasiado amplia pues incluye en su seno formas de participación ajenas a la participación política.

La democracia participativa, además, implica en el presente factores (la importancia del ámbito local, la horizontalidad en la elaboración de las decisiones políticas, la interactuación entre el poder político y la sociedad, especialmente el valor complementario de los instrumentos participativos) que difícilmente podrían encuadrarse en términos como democracia directa (ya se piense en la ateniense -la libertad de los antiguos, que dijera Constant-, ${ }^{14}$ ya en una futura merced a la utilización de herramientas informáticas), o como democracia deliberativa, la cual se asocia más a los acuerdos socialmente transversales y mayoritarios antes que a la toma de decisiones de los ciudadanos. ${ }^{15}$

De la democracia participativa se pueden predicar tanto ventajas como desventajas. ${ }^{16}$ Entre las primeras cabe destacar la mejora del intercambio de información entre las administraciones públicas y los ciudadanos; aumento de la participación de los ciudadanos; aumento de la formación cívica de los ciudadanos; identificación más intensa del ciudadano con la comunidad de la que forma parte; revalorización de la democracia como modelo político; mayor respaldo popular de las decisiones tomadas por los poderes públicos; mejora de la imagen de los políticos, de los partidos y de la política en general. Entre los segundos, el fomento del populismo; simplificación de la política; imposibilidad material de practicarla; falta de control sobre las decisiones tomadas por la ciudadanía; dinámica representativa que lleva a desnaturalizar la democracia participativa. La conocida crítica de Sartori se refiere especialmente a lo que él

\footnotetext{
${ }^{13}$ Esta opción conceptual se desarrolla en Ramirez NÁRDIZ, Alfredo. "¿Más participación igual a mejor democracia? Acerca de la crítica a la democracia participativa", Revista de Derecho Político, unED, No. 94, 2015, pp. 189-190.

${ }^{14}$ Vide Constant, Benjamin. "De la libertad de los Antiguos comparada con la de los Modernos", Escritos políticos, Centro de Estudios Constitucionales, Madrid, 1989.

${ }^{15}$ Vide FloRIDIA, ANTonIo. "La democrazia deliberativa, dalla teoria alle procedure. II caso della legge regionale toscana sulla partecipazione", Istituzioni del federalismo: rivista di studi giuridici e politici, No. 5, 2007, pp. 603-681.

${ }^{16}$ Sobre los pros vide Ramirez NÁrdiz, Alfredo. "La participación como respuesta a la crisis de la representación: El rol de la democracia participativa", Revista de Derecho Político, unED, No. 90, 2014, pp. 177-210; sobre los contras véase Ramírez NÁrdiz, Alfredo. "¿Más participación igual a mejor democracia? Acerca de la crítica a la democracia participativa", Revista de Derecho Politico, unED, No. 94, 2015, pp. 183-218.
} 
define como democracia refrendaria (esto es, las preguntas a la ciudadanía que sólo admiten elegir entre dos respuestas opuestas), a la cual califica de peligrosa y potencial amenaza a la democracia. ${ }^{17}$

En las dos últimas décadas, primero en Latinoamérica dentro del marco del nuevo constitucionalismo latinoamericano y más recientemente en Europa a raíz de la crisis económica y política, la petición de más participación directa de los ciudadanos en la toma de las decisiones políticas se ha vuelto constante. ${ }^{18}$ Las Constituciones del nuevo constitucionalismo latinoamericano (desde la colombiana de 1991 hasta la boliviana de 2009) regulan profusamente los instrumentos participativos. Los partidos políticos emergentes europeos conciben la participación como elemento esencial del nuevo discurso político, que apela a la regeneración democrática y que se extiende incluso a las formaciones políticas tradicionales. ${ }^{19}$ Parece evidente, por tanto, que la democracia participativa es una de las cuestiones constitucionales cruciales del presente, y posiblemente seguirá siéndolo en el futuro inmediato.

\section{La participación como elemento nuclear de la Constitución Política de Colombia de 1991}

Frente a la regulación de la anterior Constitución de 1886, la Constitución Política de 1991 otorga una especial importancia a la democracia participativa. ${ }^{20}$ Esta opción constitucional, que demuestra el interés del constituyente en apostar por un nuevo contrato social basado, entre otros elementos, en la implicación de los ciudadanos en su gobierno, es digna de ser especialmente destacada, más si se valora la coyuntura general en la que se encontraba Colombia en aquellos años. Era una situación de gran complejidad, tanto política, como social,

\footnotetext{
17 "la democracia refrendaria instaura, de hecho, un principio mayoritario absoluto que viola el principio (fundamentalísimo) del respeto a la minoría [...] la tan temida 'tiranía de la mayoría' -en la acepción fuerte del término - es una eventualidad poco verosímil en las democracias representativas, pero encontraría una aplicación segura en la democracia refrendaria". SARToRI, Giovanni. ¿Qué es la democracia?, Taurus, México, 2007, p. 125.

18 "Muchos críticos de las prácticas de la democracia liberal, particularmente desde la izquierda política, han tendido a creer que la obvia cura a los resultados injustos e irrazonables de las acciones de gobierno, es la de ampliar los márgenes de la participación democrática y la codeterminación". LIssidinI, Alicia. "Una mirada crítica a la democracia directa: El origen y las prácticas de los plebiscitos en Uruguay", Perfiles latinoamericanos: Revista de la Facultad Latinoamericana de Ciencias Sociales, Sede México, No. 12, 1998, p. 170.

${ }^{19}$ Indicaba, por ejemplo, la web del partido político español Podemos: "Uno de los elementos diferenciales de la nueva política es el protagonismo ciudadano, ampliando su inclusión en la construcción de iniciativas y proyectos que entre todos y todas queremos sacar adelante. Estamos demostrando que la democracia no es votar una vez cada 4 años, sino que el ejercicio de la ciudadanía se practica día a dia". Podemos. [En línea]. [Consulta: 22. Enero. 2015]. Disponible en: podemos.info

${ }^{20}$ Véase Thomas Acuña, Evaristo. Colombia: entre la crisis de la representatividad y la democracia directa, C2D, Zurich, 2008.
} 
con multitud de amenazas para el buen funcionamiento del Estado (o incluso para su propia supervivencia). Se llegaba al extremo de que grandes partes de la superficie nacional no se encontraban bajo el control de las autoridades. ${ }^{21}$

Ya en su artículo 1, la Constitución de 1991 indica que Colombia es, entre otros elementos, una república participativa. En el artículo 2 incluye entre los fines esenciales del Estado facilitar la participación de todos en las decisiones que los afectan. En el artículo 40 se apunta que "todo ciudadano tiene derecho a participar en la conformación, ejercicio y control del poder político". Para ello, además de participar en los mecanismos propios de la democracia representativa, puede ejercer instrumentos de la democracia participativa: tomar parte en plebiscitos, referendos, consultas populares, ejercer la revocatoria de mandato, o tener iniciativa en las corporaciones públicas. Se incluye también la posibilidad de los ciudadanos de interponer acciones públicas en defensa de la Constitución y la ley. El artículo 103 concreta y enumera los instrumentos participativos: el plebiscito, el referendo, la consulta popular, el cabildo abierto, la iniciativa legislativa y la revocatoria de mandato (además del voto). Este artículo remite a una ley para su desarrollo. Esta es la Ley 134 de 1994, que regula los distintos instrumentos participativos. ${ }^{22}$

a) El plebiscito. Se encuentra regulado en los artículos 77-80 y definido en el 7, cuando se indica que es el pronunciamiento del pueblo convocado por el presidente de la república mediante el cual apoya o rechaza una determinada decisión del Ejecutivo. Esta convocatoria deberá contar con la firma de los ministros y debe tratar sobre las políticas del Ejecutivo que no requieran aprobación del Congreso, excepto las relacionadas con los estados de excepción y el ejercicio de los poderes correspondientes. El presidente deberá informar inmediatamente al Congreso su intención de convocar un plebiscito, las razones para hacerlo y la fecha en que se llevará a cabo, la cual no podrá ser anterior a un mes ni posterior a cuatro, contados a partir de la fecha en que el Congreso reciba el informe del presidente.

\footnotetext{
${ }^{21}$ Como indican Alemán y Amorocho, la Constitución de 1991 "estableció instituciones y mecanismos para ampliar la representación política de las minorias y de las fuerzas distintas del bipartidismo tradicional, para tratar de reducir el clientelismo y la corrupción y para aumentar el control ciudadano sobre la actividad del Estado". ALEMÁNPeñaranda, Ivan y Amorocho-Martinez, Fabio César. "Elementos de un nuevo paradigma constitucional para la sociedad colombiana", Justicia Juris, No. 2, Universidad Autónoma del Caribe, 2001, p.73.

22 Junto con esta ley, también es especialmente relevante la Ley 131 de 1994 sobre el voto programático, el incumplimiento del cual (la promesa electoral del candidato a alcalde o gobernador a sus electores) permite que se active la revocatoria de mandato. Ambas leyes fueron reformadas por la Ley 741 de 2002. En 2015 se aprobó la Ley 1757 de 2015 (julio 6), por la cual se dictan disposiciones en materia de promoción y protección del derecho a la participación democrática, que reformó la legislación. En términos generales, esto hizo más sencillos y accesibles los distintos instrumentos participativos: simplificó su organización, facilitó su promoción por el ciudadano, bajó algunos porcentajes de participación requeridos.
} 
El plebiscito no podrá coincidir con otra elección. Cuando dentro del mes siguiente a la fecha en que el presidente haya informado sobre su intención de realizar un plebiscito, ninguna de las dos Cámaras, por la mayoría de asistentes, haya manifestado su rechazo, el presidente podrá convocarlo. En ningún caso el plebiscito podrá versar sobre la duración del periodo constitucional del mandato presidencial, ni podrá modificar la Constitución. El acceso de los partidos y movimientos políticos a los espacios de televisión financiados por el Estado se hará de conformidad con lo establecido para el referendo constitucional. El Gobierno dispondrá del mismo tiempo en televisión para expresar su opinión sobre el plebiscito. Se usarán estos espacios dentro de los veinte días anteriores a la fecha señalada para la votación. El pueblo decidirá por la mayoría del censo electoral.

b) La consulta popular. Está regulada en los artículos 50-57 y definida en el 8. Es la institución mediante la cual una pregunta general sobre un asunto de trascendencia nacional, departamental, municipal, de distrito o local, es sometida por el presidente -con firma de los ministros y con aceptación del Senado-, el gobernador o el alcalde -con aceptación del consejo o la junta administrativa local-, según el caso, a la decisión de la ciudadanía. En la consulta popular de carácter nacional, el presidente enviará el texto de la consulta al Senado para que en veinte días se pronuncie. Del mismo modo, el gobernador o el alcalde solicitarán a la asamblea, al concejo o a la junta administradora local, un pronunciamiento sobre la conveniencia de la consulta de carácter departamental, municipal o local en los mismos términos que la consulta nacional.

Si este fuere desfavorable, el gobernador o el alcalde no podrán convocar la consulta. La votación de la consulta popular nacional se realizará dentro de los cuatro meses siguientes a la fecha del pronunciamiento del Senado, o del vencimiento del plazo indicado para ello. En los demás casos, el término será de dos meses. No se pueden hacer consultas populares sobre una modificación de la Constitución. Cuando la consulta se refiere a convocar una asamblea constituyente, las preguntas serán sometidas a consideración popular mediante ley aprobada por el Congreso de la República. La decisión de la ciudadanía en la consulta popular será obligatoria. Para que esto pueda producirse, deberán ser favorables al menos la mitad más uno de los sufragios válidos emitidos; además, la participación no debe ser menor a la tercera parte de los electores que compongan el respectivo censo electoral.

c) El referendo. Regulado en los artículos 32-49 y definido en el 3. Es la convocatoria que se hace al pueblo para que apruebe o rechace un proyecto de norma jurídica o derogue o no una norma ya vigente. El primero es el referendo aprobatorio; el segundo, derogatorio. El referendo aprobatorio se da cuando se somete un proyecto de ley, de una ordenanza, de un acuerdo o de 
una resolución local de iniciativa popular, que no haya sido adoptada por la corporación pública correspondiente, a consideración del pueblo para que éste decida si lo aprueba o lo rechaza. El referendo derogatorio se da cuando se somete una ley, una ordenanza, un acuerdo o una resolución local, en alguna de sus partes o en su integridad, a consideración del pueblo para que éste decida si la deroga o no. La derogación puede ser total o parcial.

Los referendos nacionales pueden ser legales y constitucionales. El referendo constitucional requiere la iniciativa del Gobierno o el respaldo de un mínimo de 5\% del censo electoral y que el Congreso apruebe por ley su convocatoria por mayoría de ambas cámaras. Una reforma de la Constitución por referendo requiere el sufragio afirmativo de la mayoría de los votantes, y que éstos supongan más de $25 \%$ del electorado.

El único ${ }^{23}$ referendo de nivel nacional celebrado en Colombia desde la aprobación de la actual Constitución se realizó el 25 de octubre de 2003 para reformar la Constitución en materia fiscal, económica, entes de control y corrupción. Los resultados de este referendo de 2003 fueron negativos para el gobierno del presidente Uribe. De las quince reformas constitucionales planteadas sólo fue aprobada una: la relativa a la "muerte política", es decir, aquella que prohibía a personas condenadas por delitos de corrupción ser candidatos para cargos públicos o ser adjudicatarios de contratos públicos. Las otras catorce propuestas de reformas versaban sobre materias tales como los límites de las pensiones estatales o el congelamiento de los salarios de los funcionarios públicos, y ninguna fue aprobada. Se podría considerar que, en gran medida, se rechazaron debido a la propuesta de reforma del sistema de pensiones, la cual ejerció como motor para votar en contra no sólo de ella sino de las otras propuestas de reforma que formaban el referendo. ${ }^{24}$

d) La iniciativa popular. Regulada en los artículos 2 y 28 a 31 . El artículo 2 define la iniciativa popular legislativa y normativa ante las corporaciones públicas como el derecho político de un grupo de ciudadanos de presentar proyectos de acto legislativo y de ley ante el Congreso, de ordenanzas ante las asambleas departamentales, de acuerdos ante los consejos municipales o distritales y de resoluciones ante las juntas administradoras locales y demás resoluciones de las corporaciones de las entidades territoriales. Sólo pueden ser materia de iniciativa aquellas que sean de la competencia de la respectiva corporación.

\footnotetext{
${ }^{23}$ Se exceptúan las preguntas realizadas a la ciudadanía en el siglo xIX, o la realizada por la Junta Militar en 1957. Se exceptúan también aquellos de ámbito municipal para la creación o segregación de municipios que se han realizado después de 1991.

${ }^{24}$ ввс. Colombia: Confirmada derrota en referendo. [En línea]. [Citado: 20. Enero. 2016]. Disponible en: news.bbc. co.uk/hi/spanish/specials/2003/balance_2003/newsid_3364000/3364751.stm
} 
No se podrán presentar iniciativas populares ante el Congreso, las asambleas, los concejos o las juntas administradoras locales en las materias de iniciativa exclusiva del Gobierno, de los gobernadores o de los alcaldes, según lo establecido en los artículos 154, 300, 313, 315, 322 y 336 de la Constitución Política; presupuestales, fiscales o tributarias; relaciones internacionales; concesión de amnistía o indultos; preservación y restablecimiento del orden público. Para promover una iniciativa popular, ésta debe estar suscrita por 5\% de los ciudadanos inscritos en el censo electoral, si la iniciativa es de ámbito nacional, y de $10 \%$ si es de ámbito territorial inferior al nacional.

Cuando las iniciativas populares promovidas por concejales o diputados sean de ley, requerirán de un respaldo de 30\% de los concejales o diputados del país. Si la corporación correspondiente no aprueba la iniciativa, los ciudadanos pueden pedir la convocatoria de un referendo con el apoyo de no menos de 10\% de los ciudadanos del censo, tal y como señala el artículo 32 de la Ley 134. Una vez certificado el cumplimiento de los requisitos de una iniciativa por la Registraduría del Estado Civil correspondiente, su vocero presentará dicho certificado con el proyecto de articulado y la exposición de motivos, así como la dirección de su domicilio y la de los promotores, ante la Secretaría de una de las cámaras del Congreso o de la corporación pública respectiva, según el caso.

El nombre de la iniciativa, el de sus promotores y vocero, así como el texto del proyecto de articulado y su exposición de motivos deberán ser divulgados en la publicación oficial de la correspondiente corporación. El vocero deberá ser convocado a todas las sesiones en que se tramite el proyecto y ser oído en todas las etapas del trámite. Además, podrá apelar ante la plenaria cuando la comisión respectiva se haya pronunciado en contra de la iniciativa popular. Cuando la respectiva corporación no dé primer debate a una iniciativa popular durante una legislatura y ésta deba ser retirada, se podrá volver a presentar en la siguiente legislatura. En este caso, seguirán siendo válidas las firmas que apoyan la iniciativa popular y no será necesario volver a recolectarlas.

e) La revocatoria de mandato: regulada en los artículos 6 y 64 a 76 de la Ley 134, así como en la Ley 131. Es un derecho político por medio del cual los ciudadanos dan por terminado el mandato que han conferido al gobernador o al alcalde; debe ser solicitada ante la Registraduría Nacional mediante un memorial que suscriban los ciudadanos en número no inferior a 30\% de los votos que obtuvo el elegido (hasta 2015, era 40\%). La revocatoria sólo puede iniciarse cuando haya transcurrido un año como mínimo desde la toma de posesión del gobernador o el alcalde.

Siempre se deberá hacer la solicitud de votación para la revocación, exponiendo los argumentos por los cuales se pide (insatisfacción general de los 
votantes o incumplimiento del programa de gobierno del mandatario). Una vez expedida la certificación que apruebe la solicitud de realizar la revocatoria, la votación se realizará en un plazo de dos meses. El mandato del gobernador o del alcalde será revocado si la votación es aprobada en el pronunciamiento popular por la mitad más uno de los votos ciudadanos que participen en la respectiva convocatoria, siempre que el número de sufragios no sea inferior a 40\% (hasta 2015 era 55\%) de la votación válida registrada el día en que se eligió al respectivo mandatario. ${ }^{25}$

Si la revocatoria no fuera exitosa, no podrá volver a convocarse otra en el mismo mandato del gobernador o alcalde. De lo contrario, previo informe del resultado positivo al presidente de la república o el gobernador respectivo, la remoción del mandatario será inmediata y en los treinta días siguientes se celebrarán elecciones para sustituto. Durante estos treinta días, se nombrará un encargado del mismo partido del mandatario depuesto para ejercer sus funciones. Puede inscribirse como candidato a sustituto cualquier ciudadano que cumpla los requisitos constitucionales y legales para ello, de conformidad con lo establecido en las normas electorales generales, a excepción del mandatario que ha renunciado o al que le ha sido revocado el mandato. La inscripción del candidato deberá hacerse ante el correspondiente registrador del Estado Civil, por lo menos veinte días antes de la fecha de la votación. ${ }^{26}$

f) El cabildo abierto. Regulado en los artículos 9 y 81-90 de la Ley 134. El cabildo abierto es la reunión pública de los concejos distritales, municipales o las juntas administrativas locales, en la cual los habitantes pueden participar directamente a fin de discutir asuntos de interés para la comunidad. En cada periodo de sesiones deben celebrarse al menos dos sesiones para estudiar asuntos propuestos por los residentes. Estos asuntos deberán ser competencia de la corporación ante la cual se presenten (municipio, distrito, localidad, comuna o corregimiento). Para que un asunto sea discutido en cabildo abierto, la propuesta debe estar apoyada con las firmas de cinco por mil del censo electoral.

\footnotetext{
${ }^{25}$ Hasta la reforma introducida por el artículo 2 de la Ley 741 de 2002, los artículos 11 de la Ley 131 y 69 de la Ley 134 indicaban que la revocatoria se aprobaba por no menos de 60\% de los votantes y siempre que el número de votos emitido no fuera inferior a $60 \%$ de aquellos que se emitieron el día en que se eligió al mandatario revocado. Sólo podrían votar aquellos que en su día votaron para elegir al mandatario que será revocado.

${ }^{26}$ Quepa destacar, por la relevancia de la ciudad, la revocatoria presentada contra el alcalde de Bogotá, Gustavo Petro, que fue cancelada al destituirse al gobernante. Fueron presentadas 641707 firmas pidiendo la revocatoria, de las cuales se validaron 357 250, lo cual superó el umbral mínimo necesario de 289 263. Para que la revocatoria fuera aprobada se habrian necesitado 1234214 firmas favorables. La fecha de la votación era el 6 de abril de 2014 (casi un año después de entregadas las firmas el 18 de abril de 2013), pero el procedimiento comenzado en diciembre de 2013, cuando la Procuraduría General de la Nación destituyó a Petro, supuso que la revocatoria fuera cancelada. Posteriormente Petro sería restituido en su puesto. Colombia. "Registraduria Nacional del Estado Civil". [En línea]. [Citado: 22. Enero. 2016]. Disponible en: www.registraduria.gov.co/-Oficios-revocatoria-de-mandato-del-html
} 
Las organizaciones civiles pueden participar en el proceso de convocatoria y celebración de los cabildos abiertos. Al cabildo abierto puede asistir todo aquel que tenga interés en las materias que se traten en el mismo. Tienen derecho a ser oídos el vocero de quienes solicitaron el cabildo y todos los que se inscriban con un mínimo de tres días de anticipación y presenten un resumen escrito de su intervención. Puede ser materia de cabildo abierto cualquier asunto de interés para la comunidad. No pueden serlo los proyectos de ordenanza, acuerdo o cualquier otro acto administrativo. Los temas se tratan en el mismo orden en que se presentaron a la respectiva secretaría.

Si la materia del cabildo afecta específicamente a una localidad, corregimiento o comuna, el cabildo puede sesionar en cualquier sitio de ésta, con la presencia del respectivo concejo municipal o distrital, o la junta administradora local, según el caso. Los concejos municipales o distritales, o las juntas administradoras locales, deben dar amplia difusión de la fecha, el lugar y los temas del cabildo abierto. Se debe ordenar la publicación de dos convocatorias en un medio de comunicación idóneo. Terminado el cabildo, a la semana siguiente, en audiencia pública, el presidente de la corporación respectiva debe dar respuesta escrita y razonada a los planteamientos y solicitudes de la población.

Si se trata de un asunto relacionado con inversiones públicas municipales, distritales o locales, la respuesta debe dar el orden de prioridad de las mismas dentro del presupuesto y los planes correspondientes. El cabildo abierto también puede ser visto como un sistema de control de los funcionarios locales, pues por solicitud de los promotores del cabildo o por iniciativa de los voceros, previa proposición aprobada por la corporación, puede citarse a funcionarios municipales o distritales, con cinco días de anticipación, para que concurran al cabildo y para que respondan, oralmente o por escrito, sobre hechos relacionados con el tema del cabildo. La desatención inmotivada es causa de mala conducta.

\section{Análisis de la jurisprudencia de la Corte Constitucional de Colombia en materia de democracia participativa}

La Corte Constitucional colombiana fue creada por la Constitución Política de 1991. ${ }^{27}$ Entró en funcionamiento en $1992 .{ }^{28}$ Se puede considerar que la jurispru-

\footnotetext{
${ }^{27}$ Como indica Cortés Zambrano, la Constitución Política de Colombia de 1991 es expresión del Estado Constitucional, una de cuyas caracteristicas más destacadas consiste en que tanto la interpretación constitucional como la teoria de la argumentación adquieren especial relevancia. Cortés Zambrano, SoniA Patricia. "La Constitucionalización del Derecho y La Interpretación Jurídico Constitucional", Via Inveniendi et ludicandi, Universidad Santo Tomás, No. 12, 2011, pp. 10-11. ${ }^{28}$ Como señala Vargas Hernández, con la puesta en marcha de la Corte Constitucional se supera en Colombia la función de mero legislador negativo que ejercia la Corte Suprema de Justicia para llegar a una verdadera función tanto de legislador negativo, como de legislador positivo. La Corte Constitucional comenzó a ejercer un "avanzado
} 
dencia constitucional colombiana sobre democracia participativa da comienzo con las sentencias C-180/1994, de 4 de abril de 1994, que se centra en la Ley 134 de 1994, y C-011/1994, de 21 de enero de 1994, que se centra en la Ley 131 de 1994. La sentencia C-180/1994, cuyo magistrado ponente fue Hernando Herrera Vergara, aportó una definición propia de la democracia participativa y mostraba la línea jurisprudencial que seguiría la Corte Constitucional de ese momento en adelante:

En la democracia participativa el pueblo no sólo elige sus representantes por medio del voto, sino que tiene la posibilidad de intervenir directamente en la toma de ciertas decisiones, así como la de dejar sin efecto o modificar lo que sus representantes en las corporaciones públicas hayan adoptado, ya sea por convocatoria o por su propia iniciativa, y la de revocarle el mandato a quienes han elegido [...] En síntesis: la participación ciudadana dentro del sistema democrático a que se ha hecho referencia, inspira el nuevo marco sobre el cual se estructura el sistema constitucional del Estado colombiano. Ésta implica la ampliación cuantitativa de oportunidades reales de participación ciudadana, así como su recomposición cualitativa en forma que, además del aspecto político electoral, su espectro se proyecte a los planos de lo individual, familiar, económico y social.

Desde el mismo comienzo de la jurisprudencia constitucional colombiana se expone, por tanto, un concepto amplio de la democracia participativa. Amplio en el sentido de incluir en su seno multitud de instrumentos participativos (algunos de ellos, como la revocatoria de mandato, ausentes del derecho comparado en regiones como Europa), y en el de entender como participación no sólo la política, sino también aquella que se ejerce y proyecta en cualquier otro plano de la vida tanto individual como colectiva del ciudadano. En este sentido, para la sentencia C-180/1994, "el principio de democracia participativa no sólo permea el ejercicio del poder público y social, sino que además penetra ámbitos de la vida privada anteriormente excluidos de la regulación estatal. En efecto, la participación en la vida política, cívica y comunitaria del país es elevada al estatus de deber constitucional de la persona y del ciudadano".

control de constitucionalidad utilizando técnicas jurídicas de control según la experiencia tanto de tribunales constitucionales europeos como de la Suprema Corte de los Estados Unidos de América". Consideró así la Corte Constitucional que sus funciones habian de ser también las de colaborar con el legislador incluso orientando la producción de leyes. Vargas Hernández, Clara Inés. "La función creadora del Tribunal Constitucional", Derecho Penal y Criminología: Revista del Instituto de Ciencias Penales y Criminológicas, vol. 32, No. 92, 2011, p. 19. 
Como continúa indicando esta sentencia inauguradora de la jurisprudencia constitucional colombiana en esta materia, el objetivo último de la democracia participativa es una revalorización y fortalecimiento del concepto de ciudadano que lleve a replantear su papel en la vida nacional. La democracia participativa no supone sólo el otorgamiento constitucional de instrumentos con los cuales el ciudadano puede tomar partido en la vida política de país; implica que el ciudadano pueda participar en todos los procesos decisorios no electorales que afecten su vida. Así, la sentencia T-814/99 destacó que la participación no se veía sólo como un sistema de toma de decisiones, sino como un modelo de comportamiento social y político en el cual la participación, el pluralismo, la tolerancia y la protección de los derechos y libertades formaban un todo cuyo último objeto era la definición ciudadana del destino colectivo.

En esta dirección, la sentencia C-021/1996 incidió en la perspectiva amplia que de la democracia participativa tiene la Corte Constitucional colombiana. Recalca que "la democracia participativa procura otorgar al ciudadano la certidumbre de que no será excluido del debate, del análisis ni de la resolución de los factores que inciden en su vida diaria, ni tampoco de los procesos políticos que comprometen el futuro colectivo". Pues, como continúa indicando la sentencia, la participación es un principio constitucional que no se agota en el ámbito político, sino que se extiende a cualquier otro.

La Corte Constitucional ve la participación como un verdadero derecho que pueden exigir los ciudadanos y que las administraciones públicas deben suministrar en múltiples áreas. Así, por ejemplo, la sentencia C-891/2002, respecto al acceso a la información que resida en poder de las entidades estatales, indica que éstas deben suministrarla como manifestación del derecho del ciudadano a participar en la discusión constructiva con la administración. Respecto a las comunidades indigenas, señala que el Gobierno debe favorecer mecanismos que les permitan participar en los asuntos que las afecten. ${ }^{29}$

Si se analizan las distintas sentencias de la corte constitucional en conjunto, es posible observar rasgos comunes, un enfoque caracterizado por buscar objetivos concretos por lograr mediante una mayor participación:

\footnotetext{
${ }^{29}$ Como indica Cruz Martínez en relación con la línea asumida por la jurisprudencia de la Corte Constitucional, siguiendo los postulados de Rawls o de Gargarella: "la validez de una decisión mayoritaria no reside exclusivamente en que ésta haya sido adoptada mayoritariamente sino además en que esta haya sido públicamente deliberada y discutida [...] ello genera decisiones más racionales, más justas, mejor sustentadas en la justicia, mayor control ciudadano y mayores posibilidades de ser acatadas voluntariamente por sus destinatarios". Cruz Martinez, Alexander. "Influencia del pensamiento de Rawls en la jurisprudencia de la corte constitucional colombiana", Saber, ciencia y libertad, vol. 8, No. 2, 2013, p. 23.
} 
- La consagración de una auténtica soberanía popular. La sentencia de unificación SU-1122/2001 destaca que el constituyente optó por la democracia participativa para lograr una "real eficacia de la consagración de la soberanía popular".

- La consecución del interés general. La sentencia T-1182/2001, en el marco de una consulta popular sobre la circulación de vehículos a motor en la capital del país, manifiesta que los instrumentos participativos tienen una especial relevancia para que se dé a conocer el interés general mediante una votación popular.

- La lucha contra la corrupción. La sentencia C-643/2000 manifiesta que los instrumentos participativos tienen por una de sus utilidades "permitir el ejercicio de un control político, moral y jurídico de los electores por parte de los elegidos, sin intermediarios, con lo que se sanciona eficazmente la corrupción administrativa y el uso del poder en interés particular".

- Una mayor eficiencia política. La sentencia T-637/2001 apunta que "en la democracia participativa no sólo se valora más al ciudadano sino que, en razón a ello, el sistema político puede alcanzar mayores niveles de eficiencia. Un Estado en el que los ciudadanos cuentan con el derecho de tomar parte de forma directa en las decisiones a adoptar, de controlar los poderes públicos, de calificar los resultados obtenidos para exigir responsabilidad política, es un Estado en el que probablemente se logrará satisfacer en más alto grado las necesidades de sus asociados".

Esos objetivos se han de lograr evadiendo un uso interesado de los instrumentos participativos. Así, en la sentencia C-379/10, en el marco de un posible referendo de reforma constitucional, se manifiesta la voluntad de la Corte de garantizar que la participación no sea viciada por intereses económicos que traten de servirse de ella para sus fines privados.

Resulta especialmente importante destacar que, aun con la gran apuesta por ella, la jurisprudencia constitucional colombiana no concibe la democracia participativa como una dación de poder absoluto a los ciudadanos, hasta el punto de que su voluntad manifestada en un instrumento participativo se pueda imponer a las instituciones representativas del Estado. Muy al contrario, la democracia participativa se plantea como complemento, no como sustitutivo, de la democracia representativa. La Corte Constitucional, en su sentencia C-141/10, acerca de un control de constitucionalidad sobre una ley convocante a referendo, indicó que: 
El referendo como mecanismo de reforma constitucional es, siempre, manifestación del poder constituyente derivado y ni siquiera la intervención del electorado para votar la propuesta, después de haber sido tramitada en el Congreso y revisada por la Corte Constitucional, tiene la fuerza jurídica suficiente para transformar el referendo en acto constituyente fundacional, primario u originario. La noción de pueblo que acompaña la concepción de democracia liberal constitucional no puede ser ajena a la noción de pluralismo e implica la coexistencia de diferentes ideas, razas, géneros, orígenes, religiones, instituciones o grupos sociales. El pueblo de tan heterogénea composición al escoger un modelo de democracia constitucional acepta que todo poder debe tener límites y, por lo tanto, como pueblo soberano acuerda constituirse y auto limitarse de conformidad con ese modelo democrático e instituye cauces a través de los cuales pueda expresarse con todo y su diversidad. Por ello, en los Estados contemporáneos la voz del pueblo no puede ser apropiada por un solo grupo de ciudadanos, así sea mayoritario, sino que surge de los procedimientos que garantizan una manifestación de esa pluralidad.

Esta sentencia, en lectura con las anteriormente citadas, tiene crucial importancia para comprender la línea jurisprudencial general que la Corte Constitucional ha mantenido sobre la democracia participativa en las últimas décadas. Esto es, un apoyo convencido a la misma como herramienta para el progreso democrático colombiano, pero nunca superando el límite de ser un mero complemento de la representación, del modelo liberal clásico construido no alrededor del poder constituyente, sino de los poderes constituidos. Así, en la sentencia citada (C141/10), y en relación con la reforma de la Constitución, se opta por considerar que "el poder constituyente derivado tiene competencia para reformarla, mas no para sustituirla, por lo cual todo cambio de identidad del texto constitucional implica un vicio de competencia por exceso en el ejercicio del poder reformatorio". No hay que olvidar que la Constitución de 1991 fue aprobada por una asamblea constituyente, no por un referendo.

Pero la democracia participativa no es sólo participación, sino también control. Si en democracia el ejercicio de poder político implica el control político como herramienta para limitarlo, la democracia participativa pretende complementar el habitual control de unas instituciones sobre otras, con el control de los propios ciudadanos mediante diversos instrumentos participativos (desde el intercambio de información - preguntas y respuestas- con las administraciones, a una revocatoria de mandato, por citar tal vez los dos extremos). 
Así, en la sentencia T-350/14, y en el marco de una acción de tutela contra un municipio que impidió la realización de un cabildo abierto, la Corte Constitucional señaló que las decisiones de las instituciones públicas sólo son legítimas si vienen precedidas de un proceso deliberativo en el cual los ciudadanos interesados obtienen espacios concretos y efectivos de participación, pues "la participación directa busca generar espacios que permitan la formación de ciudadanos más comprometidos con las decisiones públicas, críticos y analíticos de los procesos gubernamentales”. Es decir, ciudadanos que participen, pero que utilicen dicha participación para controlar, criticar y analizar a sus gobernantes.

Una de las más recientes y relevantes sentencias de la Corte Constitucional en materia de democracia participativa es la sentencia C-150/15 (del 8 de abril de 2015), la cual, pronunciándose sobre el proyecto de nueva ley de democracia participativa,$^{30}$ indica:

La corte entiende que la participación como derecho de los ciudadanos y eje medular del ordenamiento constitucional vigente implica el deber del Estado de abstenerse de adoptar medidas de cualquier tipo que impidan el libre ejercicio de la participación por parte de los ciudadanos y organizaciones sociales, el deber de adoptar medidas de todo tipo que eviten que las autoridades públicas o los particulares interfieran o afecten el libre ejercicio de las facultades en cuyo ejercicio se manifiesta la participación, el deber de implementar medidas que procuren optimizar el desarrollo de las diversas formas de participación y que, al mismo tiempo, eviten retroceder injustificadamente en los niveles de protección alcanzados [...] La participación se manifiesta en la posibilidad que tienen todos los individuos, así como las minorías de oponerse a las determinaciones de las mayorías cuando tales decisiones tengan la aptitud de afectar los derechos que constitucionalmente les han sido reconocidos y que les permiten expresar su individualidad.

La Corte Constitucional continúa, por tanto, concibiendo la participación como eje de la democracia colombiana que surge de la Constitución de 1991. La entiende de un modo esencialmente liberal, pues la plantea no tanto como un derecho ciudadano, sino como un límite al poder del Estado, para inmediatamente añadir

\footnotetext{
${ }^{30}$ Ley 1757 de 2015 (julio 6), por la cual se dictan disposiciones en materia de promoción y protección del derecho a la participación democrática.
} 
que la participación se materializa en un método de protección de las minorias frente a las mayorías. Este enfoque dota a la jurisprudencia constitucional colombiana más reciente de una significativa relevancia. Tal como se plantea aquí, la democracia participativa, en lugar de personificar los temores sartorianos, se mostraría como herramienta de protección de los derechos individuales y de las minorías hipotéticamente atropelladas por las mayorías y no sería tanto una herramienta para el fortalecimiento del ciudadano, como un escudo protector del mismo, un arma para reaccionar frente a posibles abusos tanto del Estado como de las coyunturales mayorías que se apoderen de sus decisiones. ${ }^{31}$

En esta sentencia, la Corte Constitucional da luz sobre diversos aspectos que permiten tener una visión completa del actual momento jurisprudencial colombiano en materia participativa:

- Las formas de participación previstas en la Constitución y en la ley no agotan las posibilidades de la materia: pueden identificarse y desarrollarse otros instrumentos participativos derivado del ser expansivo de la democracia.

- Los instrumentos participativos no tienen un poder absoluto capaz de sustituir el modelo de gobierno esencialmente representativo en nombre de la voluntad popular, porque "el pueblo tiene límites para su pronunciamiento dado que la agenda la fija un grupo de ciudadanos que no actúa como poder constituyente o el Gobierno Nacional”.

- Los instrumentos participativos tienen una doble función participativa y de control: de esta segunda se indica que "tanto para los gobernantes como para los gobernados, una relación recíproca y de compromiso [...] las promesas electorales bajo el nuevo esquema constitucional deben cumplirse, lo cual explica que los electores puedan adelantar la revocatoria del mandato".

La sentencia elabora además una clasificación de los instrumentos participativos de gran interés, diferenciando entre mecanismos de conformación, de ejercicio y de control. Igualmente, aporta algunos criterios para clasificarlos:

\footnotetext{
${ }^{31}$ La sentencia llega a detallar los deberes especificos y las prohibiciones del Estado ante la participación: "El deber de abstenerse de estatizar la democracia y, en consecuencia, la obligación de proteger el pluralismo. Deber de promover formas de participación democrática que comprendan no solo la intervención de partidos o movimientos políticos sino también de organizaciones sociales de diferente naturaleza. Deber de promover estructuras democráticas en las diferentes formas de organización social. Prohibición, que vincula a todos los órganos públicos, funcionarios y particulares, de eliminar alguna de las dimensiones de la democracia. Mandato de no sustituir a las autoridades estatales competentes en el desarrollo de actividades de control".
} 
- Según el grado de intensidad participativa del ciudadano. El pueblo puede determinar quién tomará las decisiones -elección de representantes-, promover una deliberación para la toma de decisiones (cabildo abierto e iniciativa popular normativa) o adoptar él mismo una decisión (referendo, consulta popular, revocatoria del mandato y plebiscito).

- Según el papel que cumple el derecho al voto. En algunos casos, el voto impone una decisión que modifica el ordenamiento (referendo y revocatoria del mandato); en otros, obliga a aplicar una decisión (consulta popular); en otros, permite apoyar una actuación o política (plebiscito); en los demás, designa a las personas que tomarán las decisiones.

- Según el grado de intervención de las autoridades. Hay mecanismos con gran intervención de autoridades, pues a la iniciativa, la convocatoria y los resultados se les asigna prioritariamente (cabildo abierto) mecanismos con mediana intervención de autoridades. En ellos la iniciativa le corresponde a los ciudadanos; los resultados, al órgano representativo (iniciativa popular normativa). 0 bien, la iniciativa y la convocatoria son de las autoridades; los resultados, del pueblo (consulta popular y plebiscito). Y mecanismos con leve intervención de las autoridades, bien porque la iniciativa, convocatoria y resultados dependa de los ciudadanos (referendo constitucional derogatorio y revocatoria del mandato), bien porque la iniciativa y resultados sean de los ciudadanos, pero no su convocatoria -referendo constitucional aprobatorio-.

Combinando estos criterios, la sentencia diferencia entre mecanismos:

- Altamente participativos. Aquellos en los cuales se prevé la posibilidad de ejercer el voto. Dicha posibilidad implica la imposición inmediata de la decisión en caso de aprobarse y supone una reducida intervención de las autoridades en la iniciativa, convocatoria y definición de resultados.

- Poco participativos. Aquellos en los cuales no se prevé el ejercicio del 189 voto o, en caso de establecerse, no supone la imposición inmediata de una decisión y contempla una activa participación de las autoridades en las diferentes fases.

También en esta sentencia C-150/15 se hace una reflexión muy relevante sobre por qué la revocatoria de mandato no se extiende a los miembros del Poder Legislativo y se limita a alcaldes y gobernadores. La Corte Constitucional 
indica que "para las Corporaciones de elección popular no puede hablarse de mandato imperativo, pues no está en los representantes de un partido concretar todo el programa, la razón de ser, la naturaleza de los órganos colegiados es la negociación, el consenso y la conclusión en la ley de las decisiones más próximas a un ideario". Dado que el parlamentario, como ente aislado, ni crea, ni puede aplicar el programa electoral del partido político por el cual concurre a las elecciones, no resulta lógico exigirle a él en concreto responsabilidades por su hipotético incumplimiento. No se puede predicar el mandato imperativo de un parlamentario y, por tanto, tampoco una revocatoria.

Esta última sentencia sintetiza en gran medida la jurisprudencia constitucional colombiana sobre democracia participativa, que empezó en 1994 y que se caracteriza por una concepción no sólo positiva, sino esencial de la participación como herramienta de mejora democrática y motor del modelo constitucional surgido con la Constitución de 1991.

\section{Conclusiones}

El desarrollo y práctica de la democracia participativa en Colombia ha sido hasta el presente limitado, cuando no escaso. ${ }^{32}$ Como indica Mejía Quintana:

Es necesario comenzar por recordar que la Constitución del 91 no cumplió la principal expectativa para la que fue convocada, a saber, el logro de la paz y, a través de ella, la garantía de la vida. Y, sin duda, como ya se ha reconocido, más allá de sus aciertos y fortalezas en la defensa de derechos fundamentales, tampoco logró concretar lo que era otra de sus grandes aspiraciones: la de una auténtica y eficaz democracia participativa. ${ }^{33}$

Las explicaciones a los pocos instrumentos participativos que se realizan en Colombia cada año son, por supuesto, diversas. En primer lugar, los elevados porcentajes que se requieren para que estos instrumentos lleguen a buen término hacen muy complejo que en un país con tasas de participación política tan bajas un referendo, plebiscito, revocatoria o cualquier otro mecanismo

\footnotetext{
${ }^{32}$ Sólo un referendo de ámbito nacional en veinticinco años; ningún plebiscito, ni ninguna consulta popular, sólo unas pocas revocatorias y cabildos abiertos (proporcionalmente al número de municipios del pais). Para ampliar información, véase Colombia. Registraduría Nacional del Estado Civil. [En línea]. Ranking de mecanismos de participación por departamentos. [Citado: 21. Enero. 2016]. Disponible en: www.registraduria.gov.co/-Mecanismosde-Participacion,320-.html

${ }^{33}$ Mejia-Quintana, Óscar. "A dos décadas de la Constitución Política de 199", Araucaria: revista iberoamericana de filosofía, politica y humanidades, No. 29, 2013, p. 101.
} 
participativo supere los requisitos formales. ${ }^{34}$ Junto con esto, hay que tomar en cuenta las particulares circunstancias que, aun en el presente, se dan en el país y que dificultan el desarrollo de la democracia participativa y el propio progreso democrático: compra de votos, manejo de la vida política por poderes económicos o fuerzas fuera de la legalidad, violencia política, excesivo presidencialismo.

Aun y esto, la línea jurisprudencial de la Corte Constitucional y la interpretación que hace en esta materia ${ }^{35}$ ha sido clara: la participación es un mandato constitucional, uno de los elementos nucleares de la Constitución Política de 1991 y, por tanto, un bien necesario que debe desarrollarse y promoverse para la mejora del país. ${ }^{36}$ Este eje jurisprudencial esencial se complementa con un enfoque del mismo de carácter eminentemente liberal, en el cual se concibe la participación como un complemento, nunca como un sustituto de la democracia representativa. Lo más relevante es que en él se entiende la participación como una ampliación de derechos ciudadanos, pero especialmente como una limitación del poder del Estado, al cual se le exige que permita a los ciudadanos desarrollarse tanto individualmente, como de forma colectiva, y se le demanda garantizar a los colombianos la participación en todas las decisiones públicas.

Este contraste entre una teoría innovadora y una realidad escasa describe la práctica de la democracia participativa en Colombia y circunscribe la jurisprudencia de la Corte Constitucional a unos márgenes con mucha más aplicación en la teoría que en la práctica. Si bien la doctrina emanada de la Corte goza en algunos puntos de gran originalidad e interés (por ejemplo, C-150/15), su

\footnotetext{
${ }^{34}$ Por ejemplo, en relación con la revocatoria, indican Rivera y Cardona que "en Colombia desde la vigencia de la Constitución Política de 1991 hasta el año 2011 se han promovido 71 procesos de revocatoria de Alcaldes, de las cuales 47 se adelantaron entre febrero de 2009 a junio de 2012, y de estos, en 12 fueron certificadas las firmas y convocadas las elecciones, para un total de 36 convocatorias a votación, todos de ellos fallidos el intento de revocatoria, al no lograrse el umbral requerido en las urnas para el retiro del cargo del respectivo mandatario". Rivera Ardila, Ricardo y Cardona Saldarriaga, Ramiro. "La revocatoria del mandato: estudio de caso alcalde de Pradera Valle 2008-2011", Memorando de Derecho, año 2, No. 2, Universidad Libre, Seccional Pereira, 2011, p. 226.

${ }^{35}$ Insistiendo en la idea base de que "en el discurso jurídico hablar de 'interpretación' implica hablar de decisión y argumentación, y que la decisión correcta será la que descanse en los argumentos de más peso". CUchumbé HolguiN, Nelson y Molina Hincapié, Sergio. "Aproximación a la interpretación de tutela correcta desde Robert Alexy: Análisis de caso", Revista de derecho: División de Ciencias Jurídicas de la Universidad del Norte, No. 40, 2013, p. 246.

${ }^{36}$ ¿Cabría la posibilidad de que la Corte cambiara su jurisprudencia? Ciertamente, y en palabras de Salazar Cárdenas y Naranjo Velasco, "en materia constitucional las cuestiones tratadas son resueltas tomando como base una normatividad generalmente elástica, abierta e incluso ambigua, lo cual evidencia que en este área del derecho existe un amplio margen de apreciación para los jueces. Pero, como mínimo, este hipotético cambio es digno de ser dudado, tanto por el mantenimiento de una constante jurisprudencia por parte de la Corte por más de dos décadas, como por, al fin y al cabo, ser bastante evidente lo que la Constitución de 1991 considera respecto de la participación y su relevancia. Salazar Cardenas y Naranjo Velasco, Karolina. "Disertaciones sobre la fundamentación de las decisiones constitucionales", Bajo palabra: Revista de filosofía, No. 7, 2012, pp. 273-274. Se recomienda, en relación con la obligatoriedad del precedente constitucional, la consulta de la obra Lopez Medina, Diego EduARDo. El derecho de los jueces, Legis-Uniandes, Bogotá, 2002.
} 
aplicación a casos concretos ha chocado habitualmente con el poco ejercicio material de los instrumentos participativos.

No obstante, es posible observar (analizando la jurisprudencia constitucional más reciente en conjunto con las últimas iniciativas legislativas como la Ley 1757 de 2015) una marcada voluntad de los poderes públicos colombianos por mantener la decidida apuesta que la Constitución hizo por la democracia participativa. En este sentido, la jurisprudencia constitucional mantiene la voluntad de que la participación sea pilar fundamental para la plena democratización y normalización de la vida política colombiana. ${ }^{37}$

Las utilidades que la democracia participativa puede tener para Colombia son bien conocidas y han sido ampliamente desarrolladas y expuestas por la Corte Constitucional: creación de una verdadera soberanía popular, lucha contra la corrupción, optimización de la actividad política, integración de grupos sociales tradicionalmente discriminados o expulsados de la vida pública. Ante esto, es de prever que la jurisprudencia constitucional mantendrá en el tiempo una línea similar a la actual. No sólo porque la Constitución en gran medida lo determine así, sino porque resulta manifiesto que una mayor participación no puede más que beneficiar a la sociedad colombiana.

${ }_{37}$ Pues, como indica Benitez, "la misma Corte Constitucional, define a la Constitución de 1991 y al régimen político colombiano como participativo y democrático". Benitez, VIcente. "Jueces y democracia entre Ulises y los cantos de sirenas", Revista Facultad de Derecho y Ciencias Politicas, Universidad Pontificia Bolivariana, vol. 42, No. 117,2012, p. 387. 